\title{
A SPECTROGRAPHIC STUDY OF THE INTERACTING ECLIPSING BINARY RY SCUTI: AN EPISODE IN THE RAPID MASS LOSS STAGE OR A PROTOPLANETARY NEBULA? ${ }^{1}$
}

\author{
J. Sahade ${ }^{2,3,5,6}$ R. M. West, ${ }^{3,6}$ and M. Yu. Skul'sky ${ }^{4}$ \\ Received 2002 May 21; accepted 2002 September 10
}

\begin{abstract}
RESUMEN
RY Scuti, la binaria de eclipse de 11 días de período, caracterizada, en su espectro, por presentar líneas de [Fe III], ha sido reinvestigada en base a material espectrográfico obtenido en Chile, en el Observatorio Europeo Austral y en el Observatorio Interamericano de Cerro Tololo, que cubre las regiones 3400-5150 ^ y 5700-6700 Å. Fueron también analizadas observaciones en el ultravioleta obtenidas con el satélite IUE. El espectro de RY Sct es muy complejo y peculiar, y está caracterizado por varios conjuntos de líneas de emisión y de absorción. Entre las emisiones, aparece un grupo de líneas que son características de las nebulosas planetarias. El sistema está formado por una componente B0V y una compañera que parece rodeada por una envoltura opaca que emite en He II $\lambda 4686$. En la envoltura circumbinaria podemos distinguir: (a) una región de radiación diluida animada de una velocidad de $\sim-178 \mathrm{~km} \mathrm{~s}^{-1}$; (b) regiones donde se originan las líneas de resonancia de Si IV y C IV en el ultravioleta, con velocidades de -1200 y $-600 \mathrm{~km} \mathrm{~s}^{-1}$; (c) regiones que dan origen al "espectro nebular" y sugieren la existencia de una triple nebulosidad que rodea al sistema y está caracterizada por un valor de $N_{\mathrm{e}}$ probablemente mayor que $10^{4} \mathrm{~cm}^{-3}$, un valor de $T_{\mathrm{e}} \sim 15-20,000 \mathrm{~K}$ y velocidades de $-18,+9 \mathrm{y}+48 \mathrm{~km} \mathrm{~s}^{-1}$, respectivamente.
\end{abstract}

\section{ABSTRACT}

RY Scuti, the 11-day [Fe III] eclipsing binary, has been reinvestigated on the basis of spectrographic material obtained in Chile at the European Southern Observatory, La Silla, and at the Cerro Tololo Interamerican Observatory, covering the spectral regions $3400-5150 \AA$ and 5700-6700 $\AA$. Ultraviolet IUE observations were also analyzed. The spectrum of RY Sct is very complex and peculiar, being characterized by several sets of emission as well as absorption features. Among the emission features, there is a set of lines that are characteristic of planetary nebulae. The system is found to be formed by a B0V component and a companion that appears to be surrounded by an opaque envelope that emits in He II $\lambda 4686$. In the circumbinary envelope we can distinguish: (a) a region of diluted radiation that suggests a velocity of $\sim-178 \mathrm{~km} \mathrm{~s}^{-1}$; (b) regions of formation of the resonance lines of Si IV and C IV in the IUE UV, characterized by velocities of -1200 and $-600 \mathrm{~km} \mathrm{~s}^{-1}$; (c) regions that give rise to the "nebular spectrum" and suggest that there is a triple nebulosity surrounding the system with $N_{\mathrm{e}}$ probably larger than $10^{4} \mathrm{~cm}^{-3}, T_{\mathrm{e}} \sim 15-20,000 \mathrm{~K}$ and velocities of $-18,+9$ and $+48 \mathrm{~km} \mathrm{~s}^{-1}$, respectively.

Key Words: BINARIES: ECLIPSING - BINARIES, INDIVIDUAL: RY SCUTI - PROTOPLANETARY NEBULA

\footnotetext{
${ }^{1} \mathrm{~A}$ preliminary version of the paper was presented orally at IAU Symposium No. 151, August 5-9, 1991.

${ }^{2}$ Universidad Nacional de La Plata, Argentina

${ }^{3}$ ESO, Garching, Germany.

${ }^{4}$ Lviv State University, Ukraine

${ }^{5}$ Emeritus Researcher, CONICET, Argentina. Visiting As-
}

tronomer, Cerro Tololo Interamerican Observatory, National Optical Astronomy Observatory, operated by AURA, Inc. under contract with the National Science Foundation. Visiting Observer, European Southern Observatory.

${ }^{6}$ Guest Investigator, International Ultraviolet Explorer. 


\section{INTRODUCTION}

RY Scuti (HD 169515, BD -125045, MWC 295, SAO 161458, AFGL 5235S, IRAS 18227-1243; $\left.\alpha_{1950}=18^{\mathrm{h}} 22^{\mathrm{m}} 42.706 ; \delta_{1950}=-12^{\circ} 43^{\prime} 09^{\prime \prime} \cdot 24\right)$ is an eclipsing variable, first identified as such by Gaposchkin (1937). Its spectrum was classified as 'O9.7 Ibpe var.' by Walborn (1982). It is listed in Vol. III of the 'General Catalogue of Variable Stars' (Kholopov et al. 1987) as having visual magnitude 9.12 at maximum light, with eclipse depths $A_{1}=0.60 \mathrm{mag}$ and $A_{2}=0.44 \mathrm{mag}$, respectively, and with the indication that the light curve varies in shape. Ciatti et al. (1980) found that the eclipses are partial, that the primary eclipse is an occultation, and that $i=75^{\circ}$. Earlier, O'Connell (1949) had reported that the width of the primary eclipse is larger than that of the secondary eclipse, the ratio of the widths being 1.76 , and that the secondary eclipse is not midway between the deeper minima but that $t_{1}-t_{2}-P / 2=0.11$. For this reason, RY Sct has been listed among the systems that are candidates for displaying apsidal motion (Semeniuk 1968; Hegadiis 1969), although more recent photoelectric observations do not confirm O'Connell's findings (cf. Kumsiachvili 1985; Zakirov 1985).

The light of RY Sct is polarized and there is a considerable increase in intrinsic polarization during eclipse (Shakhovskoi 1965; Zellner \& Serkowski 1972).

RY Sct is located in the galactic plane, and Banaczkowski \& Dworak (1988) believe that the object is one of the most distant eclipsing binaries known in the Galaxy, at a distance of the order of $5000 \mathrm{pc}$.

Infrared observations of RY Sct have been performed in the $0.5-22 \mu \mathrm{m}$ interval and the list of references through 1986 may be found in the 'Catalogue of Infrared Observations' (Gezari et al. 1987). The observations indicate that the object is strongly reddened, making it the supergiant of earliest spectral type that shows the presence of dust formation, the infrared excess having the characteristics usually attributed to emission by silicate grains (Grasdalen et al. 1979). RY Sct is also an IRAS source (IRAS Catalogs and Atlases 1988), with IRAS fluxes of $44.28 \mathrm{Jy}$ at $12 \mu \mathrm{m}, 22.84 \mathrm{Jy}$ at $25 \mu \mathrm{m}, 22.80$ Jy at $60 \mu \mathrm{m}$, and $1034.86 \mathrm{Jy}$ at $100 \mu \mathrm{m}$, the last figure being an upper limit. RY Sct was detected by the Einstein satellite as an X-ray source in the 0.2-3.5 keV energy range; the upper flux limit being $\log \left(L_{\mathrm{X}} / \mathrm{erg} \mathrm{s}^{-1}\right)<32.92$ (cf. Chlebowski et al. 1989).

Hughes \& Woodsworth (1973) found that RY Sct is a radio source that seems to be of thermal na- ture (cf. Purton et al. 1982). Further radio observations have been reported with the VLA at $6 \mathrm{~cm}$ (Florkowski 1990, private communication) and with the Nancy telescope at $21 \mathrm{~cm}$ (Kazés 1982, private communication). However, as far as we know, these observations have not been published.

Belserene (1982, private communication) carried out a thorough analysis of the photometric observations of RY Sct available at the time, including those from the Harvard plate collection, and found that the period of the binary is "more nearly constant than had been thought". She has suggested the constant-period ephemeris

$$
T_{0}=\mathrm{JD} 2443342.456+11.124646 n \text { days }
$$

for the computation of the times of primary eclipse, which we have used throughout the paper.

From the spectroscopic point of view, RY Sct has, for a long time, attracted much interest because its spectrum is characterized by the predominance of emission features, some of which are due to [Fe III], as identified by Edlén \& Swings (1939). The first attempt to determine orbital elements is due to Popper (1943), who was able to derive, from the measurements of the Si IV 4088 absorption line, a value for the mass function of 16.7 solar masses. Popper also suggested that the total mass of the system is well in excess of 100 solar masses.

A number of descriptions of the spectrum have been published in the past, concluding that there is absorption associated with some of the emission, but there was no certainty as to whether absorption lines from the secondary component were really detected. Cowley \& Hutchings (1976), on the other hand, adopted the interpretation that the $\mathrm{H} \gamma, \mathrm{H} \beta$, He I 4471 and some of the other He I lines contain absorption components from both stars. They discussed several possible values of the parameters of the system and noted the very high Balmer emission decrement in the spectrum of the object.

An analysis of the optical and radio spectrum of RY Sct led King \& Jameson (1979) to the conclusion that the system probably consists of a B0V primary transferring mass to a hot $(\sim \mathrm{O} 5.6 \mathrm{~V})$ secondary. The system has been observed in the ultraviolet with the IUE satellite and a description of the spectrum, based on frames taken near secondary minimum, was published by Sahade et al. (1984).

\section{NEW SPECTROGRAPHIC OBSERVATIONS}

In view of the importance and the complexity of the RY Sct system, and in order to try to reach 
a better understanding of it, in 1981 a group of astronomers in the former USSR (M. B. Babaev, A. M. Cherepaschuk, M. I. Kumsiasvili, M. Yu. Skul'sky, and M. M. Zakirov) with the participation of $\mathrm{R} M$. West, initiated a coordinated campaign for the observation of the object using a variety of different techniques. Later, J. Sahade, who was planning to observe RY Sct from the Cerro Tololo Interamerican Observatory, joined in, as well as E. A. Antokhina, V. V. Golovaty, V. G. Karentinov, and L. I. Snezhko. The then USSR astronomers have already published a number of papers reporting on their results (see, e.g., Bull. Abastumani Astrophysical Observatory, vol. 58, 1985). In particular, calibrated tracings of twelve ESO spectra, obtained by R. M. West in 1981 (see below), were used by M. Yu. Skul'sky for a preliminary study (Skul'sky 1985), resulting in a provisional value for the mass ratio $\left(M_{1} / M_{2}=0.3\right)$ which was used by Antokhina \& Cherepashchuk (1988), in connection with the photometric data from Ciatti et al. (1980), Kumsiasvili (1985), and Zakirov (1985), to derive photometric elements, in particular $i=84.6$. Golovaty \& Skul'sky (1990) also used the above mentioned ESA spectra, supplemented by $27 \AA \mathrm{mm}^{-1}$ spectra from the sixmeter BTA telescope in the former USSR, to study the physical characteristics of the nebular envelope around RY Sct.

The present investigation is based on a new, complete set of ground-based and IUE spectra, the former with higher resolution and better phase coverage than had been attained earlier. They were obtained by two of us (R. M. West and J. Sahade) at the European Southern Observatory, on Cerro La Silla, in Chile, with the coudé spectrograph attached to the $152 \mathrm{~cm}$ reflector, yielding dispersions of about $12 \AA \mathrm{mm}^{-1}$ (22 spectra) and about $20 \AA \mathrm{mm}^{-1}$ (2 spectra), and by one of us (J. Sahade) at the Cerro Tololo Interamerican Observatory with a coudé spectrograph attached to the $152 \mathrm{~cm}$ reflector and giving dispersions of $\sim 9 \AA \mathrm{mm}^{-1}$ in the blue and $\sim 18 \AA \mathrm{mm}^{-1}$ in the red (9 spectra) and $\sim 18 \AA \mathrm{mm}^{-1}$ in the blue and $\sim 36 \AA \mathrm{mm}^{-1}$ in the red ( 3 spectra). The spectra cover the regions

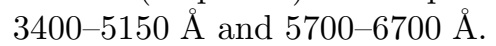

All spectra were scanned on the PDS measuring machine at the ESO headquarters and reduced by means of the HIAP image processing system installed there. A $10 \times 10 \mu \mathrm{m}$ slit was used and the photometric calibration was made by means of spot sensitometer marks (Tololo) or sensitometric spectra from the echelec facility (ESO). The wavelength scale was established by means of the Fe arc comparison spectra, the mean r.m.s. being $\sim 0.2 \AA$. The observing $\log$ is given in Table 1; the different columns containing: (a) the identification of the spectra on the ESO and CTIO archives; (b) the Heliocentric Julian Dates of mid-exposure (HJD); (c) the corresponding orbital phase derived from equation (1); (d) the exposure time in minutes; (e) the spectral range used for the present investigation; $\mathrm{f}$ ) the $\mathrm{S} / \mathrm{N}$ ratio as measured in two regions (4030-4060 $\AA$ and 4650-4675 $\AA$ ) where only few lines are present; and (g) the running number when the spectra are arranged according to phase.

Ten IUE spectra in the low dispersion, large aperture mode, were obtained by one of us (R. West) at the ESA VILSPA ground station. They were supplemented by 8 spectra from the IUE archives that were originally taken by S. Sobieski, J. Sahade and A. Michalitsianos, also in the low dispersion, large aperture mode. In total, we had at our disposal 8 images taken with the SWP camera (1165-2125 $\AA$ ) and 10 images from the LWR camera (1845-3230 $\AA$ ).

\section{THE ULTRAVIOLET SPECTRUM}

According to Sahade et al. (1984), the ultraviolet (IUE) spectrum of RY Sct corresponds to an object with $T_{\mathrm{e}}=30,000 \mathrm{~K}$ (spectral type B0) and $\log g=4.0$. The line identifications by these authors are, in general, confirmed, the most important addition referring to the presence of $\mathrm{N} \mathrm{V}$ in emission; on some of the spectra, these lines appear to have P Cyg-type profiles. This is certainly the case for the resonance lines of Si IV and C IV, where the P Cyg absorptions indicate velocities of -1200 and $-600 \mathrm{~km} \mathrm{~s}^{-1}$, respectively.

A careful examination of the SWP spectra did not reveal any changes with phase. As for the LWR spectra, they are noisy and do not allow us to ascertain whether the Mg II feature at $2800 \AA$ is actually absent at primary eclipse, as they would seem to suggest.

Table 2 contains the updated list of line identifications in the $I U E$ wavelength range.

\section{THE PHOTOGRAPHIC SPECTRUM}

The spectrum of RY Sct is rich in lines, very complex and unusually peculiar. It is characterized by the presence of emission as well as absorption features that blend together, making the derivation of orbital radial velocities from them extremely difficult. Table 3 lists the elements with a couple of relevant comments. 
TABLE 1

OBSERVATION LOG: SPECTROGRAPHIC OBSERVATIONS

\begin{tabular}{|c|c|c|c|c|c|c|}
\hline Identifier & HJD $(2,440,000+)$ & Phase & Exposure $^{\mathrm{a}}$ & Range $(\AA)$ & $\mathrm{S} / \mathrm{N}$ & No. \\
\hline \multicolumn{7}{|c|}{ ESO Spectra } \\
\hline G11990 & 4775.7554 & 0.840 & 281 & $3470-5095$ & 21 & 25 \\
\hline G11991 & 4776.7002 & 0.925 & 300 & $3470-5095$ & 9 & 29 \\
\hline G11992 & 4777.6460 & 0.010 & 300 & $3470-5095$ & 19 & 1 \\
\hline G11993 & 4777.8155 & 0.025 & 120 & $3850-4915$ & 8 & 2 \\
\hline G11998 & 4778.5818 & 0.094 & 111 & $3470-5095$ & 21 & 3 \\
\hline G11999 & 4778.6926 & 0.104 & 192 & $3470-5095$ & 25 & 4 \\
\hline G12000 & 4778.8231 & 0.116 & 164 & $3470-5095$ & 19 & 5 \\
\hline G12004 & 4779.6252 & 0.188 & 206 & $3470-5095$ & 23 & 8 \\
\hline G12005 & 4779.7585 & 0.200 & 152 & $3470-5095$ & 24 & 9 \\
\hline G12006 & 4779.8599 & 0.209 & 120 & $3470-5095$ & 14 & 11 \\
\hline G12010 & 4780.5950 & 0.275 & 169 & $3470-5095$ & 24 & 14 \\
\hline G12011 & 4780.7252 & 0.287 & 188 & $3470-5095$ & 25 & 15 \\
\hline G12579 & 5119.6822 & 0.756 & 150 & $3470-5095$ & 16 & 21 \\
\hline G12580 & 5119.7853 & 0.765 & 133 & $3470-4755$ & 23 & 22 \\
\hline G12581 & 5119.8891 & 0.774 & 150 & $3470-5095$ & 18 & 23 \\
\hline G12587 & 5120.6916 & 0.846 & 141 & $3670-5060$ & 16 & 26 \\
\hline G12588 & 5120.8190 & 0.858 & 210 & $3470-5095$ & 24 & 27 \\
\hline G12594 & 5123.7261 & 0.119 & 180 & $3470-5095$ & 21 & 6 \\
\hline G12595 & 5123.8594 & 0.131 & 186 & $3470-5095$ & 25 & 7 \\
\hline G12600 & 5124.7011 & 0.207 & 236 & $3470-5010$ & 24 & 10 \\
\hline G12601 & 5124.8498 & 0.220 & 136 & $3470-5010$ & 17 & 12 \\
\hline F07994 & 5182.6034 & 0.412 & 225 & $5750-6685$ & $\cdots$ & $\cdots$ \\
\hline G12664 & 5183.5451 & 0.496 & 194 & $3470-5050$ & 17 & 18 \\
\hline F08001 & 5184.5311 & 0.585 & 172 & $5750-6685$ & $\cdots$ & $\cdots$ \\
\hline \multicolumn{7}{|c|}{ CTIO Spectra $^{b}$} \\
\hline D01237 & 4802.5846 & 0.252 & 214 & & 7 & 13 \\
\hline D01241 & 4803.5547 & 0.339 & 180 & $3470-5095$ & 16 & 16 \\
\hline D01249 & 4804.7957 & 0.450 & 249 & & 2 & 17 \\
\hline D01252 & 4805.7283 & 0.534 & 360 & $3615-4900$ & 11 & 19 \\
\hline D01257 & 4807.5997 & 0.703 & 391 & $3850-4885$ & 10 & 20 \\
\hline D01260 & 4808.6024 & 0.793 & 335 & $3470-4940$ & 11 & 24 \\
\hline D01263 & 4809.5344 & 0.876 & 235 & $3470-4940$ & 13 & 28 \\
\hline
\end{tabular}

${ }^{\mathrm{a}}$ In minutes. $\quad{ }^{\mathrm{b}}$ The red plates (5750-6685 $\AA$ ) were obtained simultaneously; they are all very good. 
TABLE 2

THE IUE SPECTRUM OF RY SCUTI

\begin{tabular}{|c|c|c|}
\hline Wavelength $(\AA)$ & Character $^{\mathrm{a}}$ & Identification \\
\hline 1240.6 & $\mathrm{E}$ & $\mathrm{NV}(1)$ \\
\hline 1258 & $\mathrm{~A}$ & $\begin{array}{l}\text { S II(1) 53.79, 59.53, 50.50; } \\
\text { Fe II(9) 60.54; SiII(4) 64.74, } 60.42\end{array}$ \\
\hline 1299.2 & $\mathrm{~A}$ & Si III(1) $98.66,94.67$ \\
\hline 1333 & $\mathrm{~A}$ & C II(1) $34.5323,35.6627,35.1077$ \\
\hline 1390.3 & $\mathrm{~A}$ & Si IV(1) 93.755 \\
\hline 1393 & $\mathrm{E}$ & Si IV(1) 93.755 \\
\hline 1398 & $\mathrm{~A}$ & Si IV(1) 02.770 \\
\hline 1403 & $\mathrm{E}$ & Si IV(1) 02.770 \\
\hline 1422 & $\mathrm{~A}$ & C III( ) 20.033, 20.438, 21.640, 21.755, 22.408 \\
\hline 1454 & $\mathrm{~A}$ & C II(5) 55.194 \\
\hline 1494 & $\mathrm{~A}$ & C II(3) 98.697 \\
\hline 1532 & $\mathrm{~A}$ & P II(1) $32.51,35.90,36.39,42.29,43.09,43.61$ \\
\hline 1545 & $\mathrm{~A}$ & $\mathrm{C}$ IV(1) $48.185,50.774$ \\
\hline 1553 & $\mathrm{E}$ & $\mathrm{C} \operatorname{IV}(1) 48.185,50.774$ \\
\hline 1588 & $\mathrm{E}$ & {$[\mathrm{Ne} \mathrm{V}] 74.8$} \\
\hline $1598-1633$ & $\mathrm{~A}$ & Si III(1) 98.002, 3.064, 10.094; Fe (8) \\
\hline 1654 & $\mathrm{~A}$ & Fe II $(40,41) 59.49,58.78$ \\
\hline 1669 & $\mathrm{~A}$ & $\mathrm{Al} \mathrm{II}(2) 70.7867$ \\
\hline 1694 & $\mathrm{~A}$ & Fe II(38) 02.043 \\
\hline $1710-32$ & $\mathrm{~A}$ & $\begin{array}{l}\text { Fe II }(38) \text { 12.977, 20.616; Al II (6) } \\
19.4400,21.2436,21.2714,26.39\end{array}$ \\
\hline 1851 & $\mathrm{~A}$ & $\mathrm{Al} \mathrm{III(1)} \mathrm{54.72,} \mathrm{62.78;} \mathrm{Al} \mathrm{II(4)} \mathrm{55.93,} 62.31$ \\
\hline 2338 & $\mathrm{~A}$ & Fe II(3) $32.798,43.495,38.005,44.278$ \\
\hline 2362 & $\mathrm{~A}$ & Fe II(3) 59.11, 64.82 \\
\hline 2391 & $\mathrm{~A}$ & Fe II(2) 95.63, 82.03, 88.63, 99.241, 99.237 \\
\hline 2410 & $\mathrm{~A}$ & Fe II(2) 04.88, 10.52, 13.31, 06.66, 11.06 \\
\hline $2580^{\mathrm{b}}$ & $\mathrm{A}$ & $\begin{array}{l}\text { Fe II(1) 85.88, 98.37, 99.40, 07.09 and also } 11.87, \\
13.82,17.62,21.67,25.66,28.29,31.05,31.32\end{array}$ \\
\hline 2820 & $\mathrm{~A}$ & $\operatorname{Mg} I(1) 52.127(1000)$ \\
\hline
\end{tabular}

${ }^{\mathrm{a}} \mathrm{A}$ : absorption; E: emission ${ }^{\mathrm{b}}$ Possibly partly superimposed on reseau mark. 
TABLE 3

\section{ELEMENTS PRESENT IN THE SPECTRUM OF RY SCUTI}

\begin{tabular}{l}
\hline Element/Ion \\
\hline $\mathrm{H}^{\mathrm{a}}$ \\
$\mathrm{He}$ I, He II \\
C II, C III \\
N II, [N II], N III \\
[O I]?, O II, [O II], [O III] \\
Ne II, [Ne III]? \\
Mg II \\
$\mathrm{Al}$ III \\
Si II?, Si III, Si IV \\
S III, [S III]? \\
Ca I, Ca II \\
Mn II \\
[Fe III] \\
[Ni III]
\end{tabular}

${ }^{\mathrm{a}}$ At least up to H24, probably up to the Balmer limit.

${ }^{\mathrm{b}} \mathrm{He}$ II only as a broad emission at $\lambda 4686 \AA$.

\subsection{The Emission Spectrum}

Four major systems can be distinguished in the emission spectrum:

(a) Very strong, relatively narrow features that show in the nebular lines: of [N II] 6766, 6549 (Fig. 1) and 6584; [O III] 4383 (very weak), 4959 and 5007; [O II] 3726, 3729; in the transitions of [Fe III], [O I], [S III] and [Ni III], and in the permitted transitions of $\mathrm{H}$ (Fig. 1 also shows $\mathrm{H} \alpha$ ), $\mathrm{He}$ and $\mathrm{Al}$ III. In what follows we will refer to these lines as the E1 emission system.

(b) A set of broad hydrogen emissions (E2) (cf. Fig. 2, redward of the emission referred to in (a)), apparently part of broad P Cyg profile.

(c) A broad, rather faint emission at $4560 \AA$ (E3) (Fig. 3), so far unidentified, present in symbiotic and other emission-line objects (cf. Meinel, Aveni \& Stockton 1968)

(d) A broad emission of He II 4686 (E4) (Fig. 4).

\subsubsection{The E1 Emission System (cf. Table 4)}

The E1 emission system comprises threee distinct velocity components in $\mathrm{H} \alpha$ (Fig. 5) and in $\mathrm{H} \beta$ (Fig. 6). The components in $\mathrm{H} \alpha$, found by means of iterative Gaussian profile-fitting, have velocities $+46.4,+6.8$ and $-16.0 \mathrm{~km} \mathrm{~s}^{-1}$, respectively. In $\mathrm{H} \beta$, the corresponding velocities are $+48.9,+11.2$ and

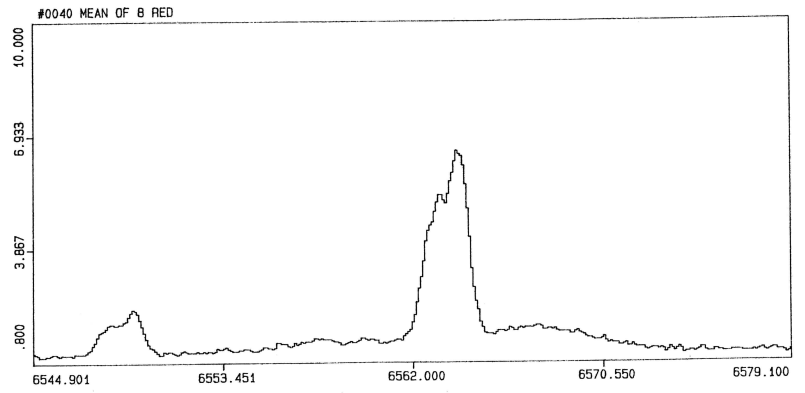

Fig. 1. The region of [N II] $\lambda 6549$ and $\mathrm{H} \alpha$ in the spectrum of RY Sct. The ordinate scale is arbitrary, and the figures on the abscissae are $\AA$.

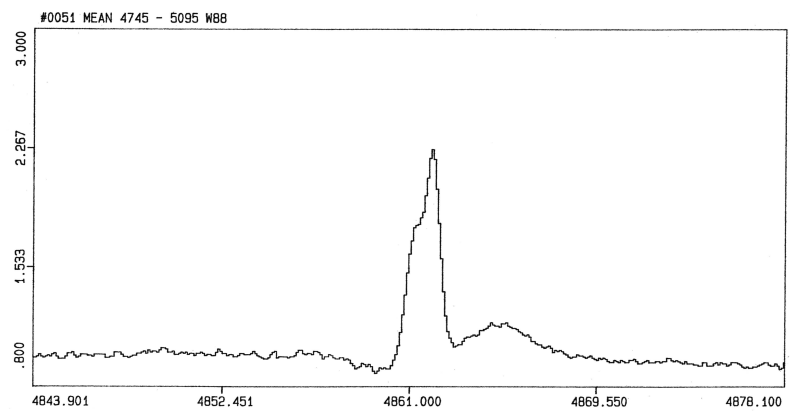

Fig. 2. The region of $\mathrm{H} \beta$ in the spectrum of RY Sct. The ordinate scale is arbitrary, and the figures on the abscissae are $\AA$.

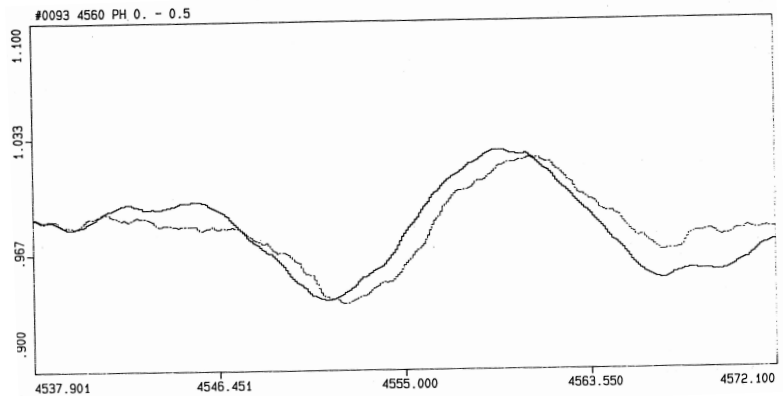

Fig. 3. The feature at $\lambda 4560$ in the espectrum of RY Sct. The ordinate scale is arbitrary, and the figures on the abscissae are $\AA$. 


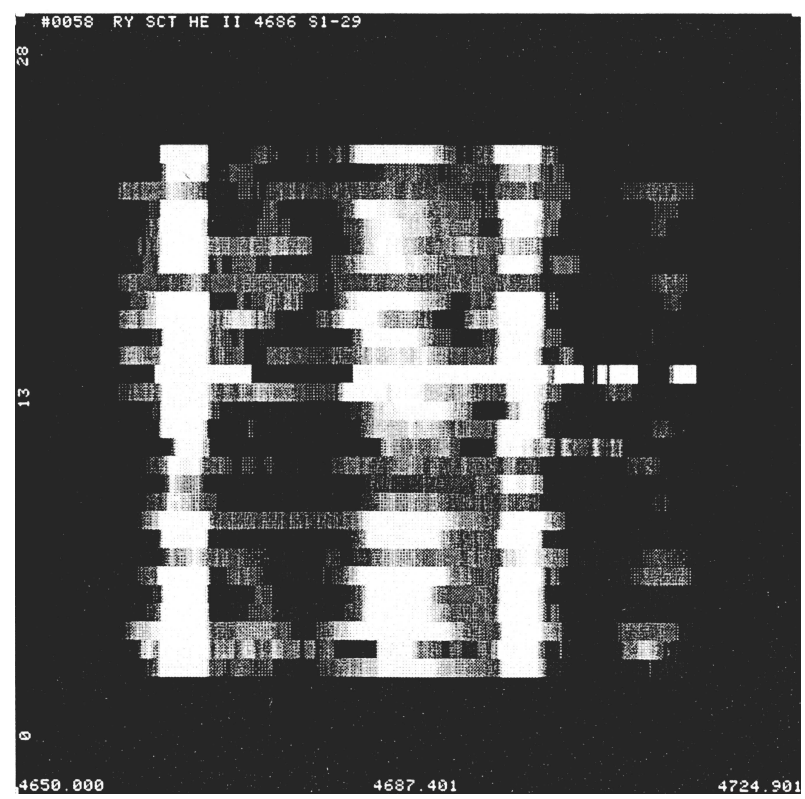

Fig. 4. The region of the broad emission of He II $\lambda 4686 \AA$ in the spectrum of RY Sct, throughout the orbital cycle. Strip number 13 corresponds to phase 0.252. Phases increase from bottom upwards.

$-18.3 \mathrm{~km} \mathrm{~s}^{-1}$. In neither of these lines could a good fit be obtained with two Gaussians only, and the near-perfect three-component fits make the presence of further components unlikely. In $\mathrm{H} \gamma$ (Fig. 7), the three components are still there, but it was possible to separate the two most violet ones only if their velocities were assumed equal to the mean of those measured at $\mathrm{H} \alpha$ and $\mathrm{H} \beta$. If we designate the three components as a, b and c, in order of decreasing velocity, their mean equivalent widths, in $\AA$ and their mean velocity $\langle V\rangle$ in $\mathrm{km} \mathrm{s}^{-1}$, are as given in Table 6 .

Most of the remaining strong, relatively narrow emission lines appear double. The mean values of the radial velocities from the two components are $+48.4 \pm 1.0 \mathrm{~km} \mathrm{~s}^{-1}$ (32 lines) and $+3.9 \pm 1.4 \mathrm{~km} \mathrm{~s}^{-1}$ (32 lines), respectively, indicating that the shortward component is actually a blend of the two violet components (b and c) that are definitely present in the first members of the Balmer series.

The E1 emissions do not appear to vary in velocity with the phase of the orbital motion. The equivalent widths of the nebular lines and the radial velocities of the components, measured on the mean spectrum, are also listed in Table 4 . The total equivalent widths agree reasonably well with those of Golovaty \& Skul'sky (1990), although these authors do not separate the individual components. The [N II] lines that are in the neighborhood of $\mathrm{H} \alpha$ are shown in Figs. 8 and 9 . The spectral range of our material
TABLE 5

THREE-GAUSSIAN FITS TO H $\beta$, $\mathrm{H} \alpha$ AND [N II] 6584

\begin{tabular}{lcc}
\hline & $\begin{array}{c}\text { Peak Wavelength } \\
(\AA)\end{array}$ & $\begin{array}{c}\text { Radial Velocity } \\
\left(\mathrm{km} \mathrm{s}^{-1}\right)\end{array}$ \\
\hline $\mathrm{H} \beta$ & 4861.05 & -17.5 \\
& 4861.50 & +10.2 \\
& 4862.11 & +47.8 \\
\hline $\mathrm{H} \alpha$ & 6562.29 & -23.0 \\
& 6562.89 & +3.5 \\
& 6563.84 & +46.8 \\
\hline$[\mathrm{N} \mathrm{II}]$ & 6583.30 & -13.5 \\
& 6583.80 & +9.0 \\
& 6584.63 & +47.0 \\
\hline
\end{tabular}

TABLE 6

THREE-GAUSSIAN FITS TO BALMER LINES

\begin{tabular}{|c|c|c|c|c|}
\hline \multirow[b]{2}{*}{ Component } & \multicolumn{3}{|c|}{ Equivalent Width $(\AA)$} & \multirow{2}{*}{$\begin{array}{c}\langle V\rangle \\
\left(\mathrm{km} \mathrm{s}^{-1}\right)\end{array}$} \\
\hline & $\mathrm{H} \alpha$ & $\mathrm{H} \beta$ & $\mathrm{H} \gamma$ & \\
\hline a & 3.600 & 0.862 & 0.263 & +47.7 \\
\hline $\mathrm{b}$ & 1.782 & 0.477 & 0.131 & +9.0 \\
\hline $\mathrm{c}$ & 1.134 & 0.342 & 0.100 & -17.6 \\
\hline
\end{tabular}

covers the regions of the forbidden lines [O II] at 3729 $\AA$ and $3727 \AA$ and $[\mathrm{N} \mathrm{II}]$ at $5755 \AA$ and $6584 \AA$ the ratios of which can provide the values of $T_{\mathrm{e}}$ and $N_{\mathrm{e}}$ that characterize the nebulosity responsible for them (cf. Gurzadyan 1969, Osterbrock 1989, Eissner et al. 1969, Seaton \& Osterbrock 1957, Nussbaumer 1971). However, in our material the [O II] pair is faint and the reality of the feature at $3729 \AA$ is doubtful. As a result, from the present material one can only say that $N_{\mathrm{e}}$ is most probably greater than $10^{4} \mathrm{~cm}^{-3}$ and that $T_{\mathrm{e}} \sim 15,000-20,000 \mathrm{~K}$.

On the other hand, the Balmer decrement is steeper in RY Sct than in planetary nebulae and, as a consequence, the plot of $\log [F(\mathrm{H} \gamma) / F(\mathrm{H} \beta)]$ versus $\log [F(\mathrm{H} \alpha) / F(\mathrm{H} \beta)]$ falls outside the theoretical predictions as well as outside the empirical distribution of values for planetary nebulae that are shown in Barker (1974). The departures are in the sense of a steeper Balmer decrement, and consequently a smaller density (cf. Miyamoto 1952), in RY Sct than in planetary nebulae. The ratios between the intensities of the strongest components in [O III] 5007, [O III] 4959 and $\mathrm{H} \beta, 0.3: 0.009: 1$, are in the range of values found in diffuse nebulae but not in planetary 
TABLE 4

STRONG, NARROW EMISSION FEATURES IN THE SPECTRUM OF RY SCUTI ${ }^{\mathrm{a}}$

\begin{tabular}{|c|c|c|c|c|c|c|}
\hline \multirow{3}{*}{$\frac{\text { Ion }}{\text { H } 14}$} & \multirow{4}{*}{$\frac{\lambda_{0}(\AA)}{3721.940}$} & \multirow{3}{*}{$\frac{\lambda_{\text {obs }}(\AA)}{21.90}$} & \multirow[b]{2}{*}{ EW $(\AA)$} & \multicolumn{3}{|c|}{ Radial Velocity $\left(\mathrm{km} \mathrm{s}^{-1}\right)$} \\
\hline & & & & \multirow[t]{2}{*}{ single-peaked } & \multicolumn{2}{|c|}{ double-peaked } \\
\hline & & & & & +3.2 & \\
\hline & & 22.30 & & & & +31.4 \\
\hline [O II $]$ & 3726.16 & 26.60 & 0.022 & +35.4 & & \\
\hline$[\mathrm{O} \mathrm{II}]$ & 3728.91 & 28.80 & 0.019 & -8.8 & & \\
\hline \multirow[t]{2}{*}{ H 12} & 3750.154 & 50.15 & & & -0.3 & \\
\hline & & 50.84 & & & & +54.9 \\
\hline \multirow[t]{2}{*}{ H 11} & 3770.632 & 70.65 & & & +1.4 & \\
\hline & & 71.30 & & & & +53.1 \\
\hline \multirow[t]{2}{*}{ H 10} & 3797.900 & 98.05 & & & +11.8 & \\
\hline & & 98.58 & & & & +51.3 \\
\hline He I & 3819.697 & 20.35 & & +42.1 & & \\
\hline \multirow[t]{2}{*}{ H 9} & 3835.386 & 35.35 & & & +2.8 & \\
\hline & & 36.00 & & & & +48.2 \\
\hline He I & 3888.646 & 89.30 & & +50.5 & & \\
\hline \multirow[t]{2}{*}{$\mathrm{H} \epsilon$} & 3970.074 & 70.15 & & & +5.7 & \\
\hline & & 70.70 & & & & +47.3 \\
\hline$[\mathrm{Fe} \mathrm{III}]$ & 4008.3 & 08.35 & & +3.7 & & \\
\hline \multirow[t]{2}{*}{ He I } & 4026.218 & 26.30 & & & +6.1 & \\
\hline & & 26.90 & & & & +50.8 \\
\hline [Fe III $]$ & 4046.4 & 45.75 & & -48.2 & & \\
\hline$[\mathrm{Fe} \mathrm{III}]$ & 4079.7 & 80.60 & & +66.2 & & \\
\hline$[\mathrm{Fe} \mathrm{III}]$ & 4096.6 & 96.01 & & -43.2 & & \\
\hline $\mathrm{H} \delta$ & 4101.737 & 02.40 & & +48.5 & & \\
\hline \multirow[t]{2}{*}{ He I } & 4120.857 & 20.50 & & & -26.0 & \\
\hline & & 21.40 & & & & +39.5 \\
\hline \multirow[t]{2}{*}{ [Fe III] } & 4144.3 & 43.85 & & -32.6 & & \\
\hline & & & 0.100 & & & \\
\hline \multirow{2}{*}{$\mathrm{H} \gamma$} & 4340.468 & 40.55 & 0.131 & & +5.7 & \\
\hline & & 41.20 & 0.263 & & & +50.6 \\
\hline \multirow[t]{2}{*}{ He I } & 4387.928 & 87.90 & & & +1.9 & \\
\hline & & 88.75 & & & & +56.2 \\
\hline \multirow[t]{2}{*}{ He I } & 4471.508 & 71.60 & 0.219 & & +6.2 & \\
\hline & & 72.25 & 0.375 & & & +49.8 \\
\hline \multirow[t]{2}{*}{ [Fe III] } & 4607.0 & 07.10 & & & +6.5 & \\
\hline & & 07.85 & & & & +55.4 \\
\hline \multirow[t]{2}{*}{$\mathrm{Fe} \mathrm{III]}$} & 4658.1 & 58.20 & 0.467 & & +6.4 & \\
\hline & & 58.90 & 0.584 & & & +51.5 \\
\hline \multirow[t]{2}{*}{ [Fe III] } & 4701.5 & 01.60 & 0.259 & & +6.4 & \\
\hline & & 02.40 & 0.338 & & & +57.4 \\
\hline \multirow[t]{2}{*}{ [Fe III] } & 4733.9 & 34.00 & & & +6.4 & \\
\hline & & 34.65 & & & & +47.5 \\
\hline
\end{tabular}


TABLE 4

(CONTINUED)

\begin{tabular}{|c|c|c|c|c|c|c|}
\hline \multirow[b]{2}{*}{ Ion } & \multirow[b]{2}{*}{$\lambda_{0}(\AA)$} & \multirow[b]{2}{*}{$\lambda_{\mathrm{obs}}(\AA)$} & \multirow[b]{2}{*}{$\mathrm{EW}(\AA)$} & \multicolumn{3}{|c|}{ Radial Velocity $\left(\mathrm{km} \mathrm{s}^{-1}\right)$} \\
\hline & & & & single-peaked & & -peaked \\
\hline \multirow[t]{2}{*}[\mathrm{Fe}\mathrm{III}]{} & 4754.7 & 54.90 & & & +12.6 & \\
\hline & & 55.50 & & & & +50.5 \\
\hline \multirow{2}{*}{ [Fe III $]$} & 4769.4 & 69.55 & & & +9.4 & \\
\hline & & 70.20 & & & & +50.3 \\
\hline \multirow[t]{2}{*}[\mathrm{Fe}\mathrm{III}]{} & 4777.7 & 77.65 & & & -3.1 & \\
\hline & & 78.45 & & & & +47.1 \\
\hline \multirow[t]{2}{*}[\mathrm{Fe}III]{} & 4813.9 & 14.35 & & +28.0 & & \\
\hline & & & 0.342 & & & \\
\hline \multirow[t]{2}{*}{$\mathrm{H} \beta$} & 4861.332 & 61.56 & 0.477 & & +14.1 & \\
\hline & & 62.10 & 0.862 & & & +47.4 \\
\hline \multirow[t]{2}{*}[\mathrm{Fe}\mathrm{III}]{} & 4881.0 & 81.00 & & & 0 & \\
\hline & & 81.75 & & & & +46.1 \\
\hline He I & 4921.929 & 22.75 & & +50.0 & & \\
\hline$[\mathrm{Fe}$ III $]$ & 4930.5 & 31.45 & & +57.8 & & \\
\hline \multirow[t]{2}{*}[\mathrm{O}\text{III}]{$\mathrm{N}$} & 4958.91 & 58.80 & 0.054 & & -6.7 & \\
\hline & & 59.75 & 0.079 & & & +50.8 \\
\hline \multirow[t]{2}{*}[\mathrm{O}\text{III}]{$\mathrm{N}$} & 5006.84 & 06.85 & 0.244 & & +0.6 & \\
\hline & & 07.65 & 0.272 & & & +48.5 \\
\hline \multirow[t]{2}{*}[\mathrm{Fe}\mathrm{III}]{} & 5011.3 & 11.25 & & & -3.0 & \\
\hline & & 11.95 & & & & +38.9 \\
\hline \multirow[t]{2}{*}[\mathrm{Fe}\mathrm{III}]{} & 5047.736 & 47.65 & & & -5.1 & \\
\hline & & 48.39 & & & & +38.7 \\
\hline \multirow[t]{2}{*}{ He I } & 5015.675 & 15.75 & & & +4.5 & \\
\hline & & 16.50 & & & & +49.3 \\
\hline \multirow[t]{2}{*}[\mathrm{N}\text{II}]{$\mathrm{N}$} & 5754.8 & 54.90 & 0.217 & & +5.2 & \\
\hline & & 55.60 & 0.362 & & & +41.7 \\
\hline \multirow[t]{2}{*}{ He I } & 5875.666 & 75.80 & & & +6.8 & \\
\hline & & 76.60 & & & & +47.7 \\
\hline$[\mathrm{O} \mathrm{I}]$ & 6300.23 & 00.30 & & +3.3 & & \\
\hline \multirow[t]{2}{*}{ [S III] } & 6312.1 & 12.26 & & & +7.6 & \\
\hline & & 13.08 & & & & +46.6 \\
\hline \multirow[t]{2}{*}{ [Ni III] } & 6401.5 & 02.00 & & +23.4 & & \\
\hline & & & 0.747 & & & \\
\hline \multirow[t]{2}{*}[\mathrm{N}\mathrm{II}]{} & 6548.1 & 48.39 & 0.7149 & & +13.1 & \\
\hline & & 49.20 & 1.046 & & & +50.4 \\
\hline \multirow[t]{3}{*}{$\mathrm{H} \alpha$} & 6562.817 & & 1.134 & & & \\
\hline & & 63.10 & 1.782 & & +12.9 & \\
\hline & & 63.90 & 3.660 & & & +49.5 \\
\hline \multirow[t]{3}{*}[\mathrm{N}\text{II}]{$\mathrm{N}$} & 6583.6 & & 2.136 & & & \\
\hline & & 83.80 & 0.974 & & +9.1 & \\
\hline & & 84.60 & 3.512 & & & +45.6 \\
\hline He I & 6678.149 & 78.40 & & & +11.3 & \\
\hline & & 79.40 & & & & +56.2 \\
\hline
\end{tabular}

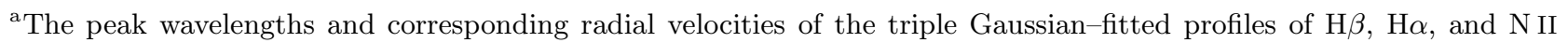
6584 are given in Table 5. 


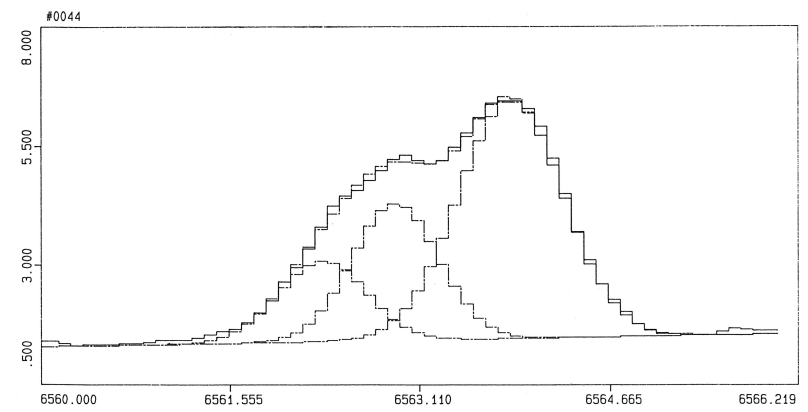

Fig. 5. The $\mathrm{H} \alpha$ line profile in the spectrum of RY Sct as the sum of 3 components. The ordinate scale is arbitrary, and the figures on the abscissae are $\AA$.

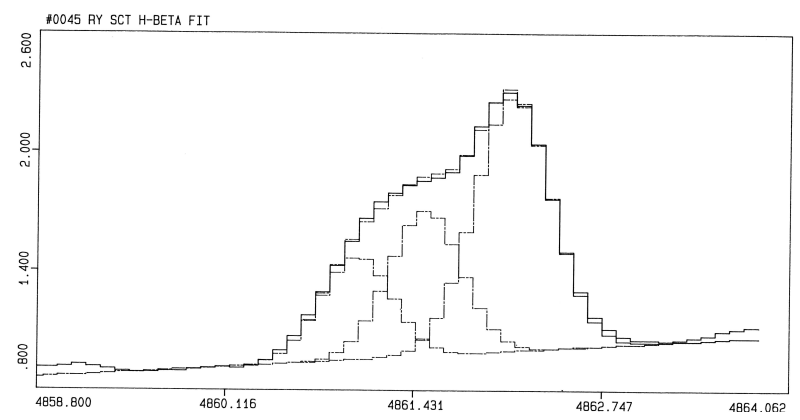

Fig. 6. The $\mathrm{H} \beta$ line profile in the spectrum of RY Sct as the sum of 3 components. The ordinate scale is arbitrary, and the figures on the abscissae are $\AA$.

nebulae (cf. Gurzadyan 1969). Moreover, the ratios measured in RY Sct,

$$
I([\mathrm{O} \mathrm{III}] 5007+[\mathrm{O} \mathrm{III}] 4959) / I(\mathrm{H} \beta)=0.4,
$$

and

$$
I([\mathrm{~N} \mathrm{II}] 5755+[\mathrm{N} \mathrm{II}] 6584) / I(\mathrm{H} \beta)=5,
$$

are also outside the values that are typical of planetary nebulae: $+1.8,-20.2$ and -1 , respectively (Gurzadyan 1969).

\subsubsection{The E2 Emission System (cf. Table 4)}

The broad E2 emission system that can be seen in Figs. 5 and 6 does not appear to display significant variations in velocity with phase.

\subsubsection{The E3 Emission System}

As can be seen in Fig. 3, the velocity of the broad emission at about $4560 \AA$ appears to follow the same trend as Si IV 4088 (§ 4.2.2) and H9 (§ 4.2.1), but with a smaller amplitude, of the order of $-67 \mathrm{~km} \mathrm{~s}^{-1}$. It should be noted that the feature is bordered and certainly affected by the absorptions of Si III 4552

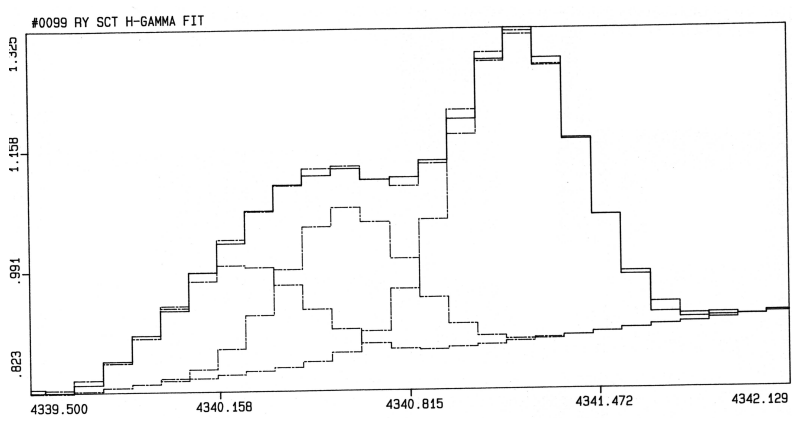

Fig. 7. The $\mathrm{H} \gamma$ line profile in the spectrum of RY Sct where the two most violet components (1 and 2) that are detected at $\mathrm{H} \alpha$ and $\mathrm{H} \beta$, cannot be distinguished separately in this case. The ordinate scale is arbitrary, and the figures on the abscissae are $\AA$.

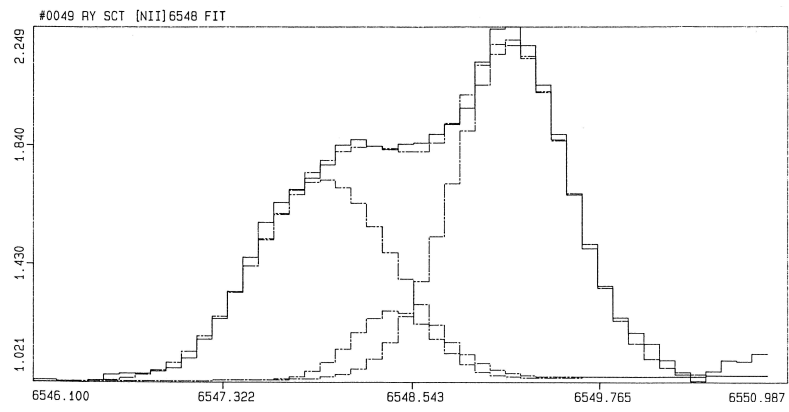

Fig. 8. Components in the [N II] $\lambda 6548$ line of the spectrum of RY Sct. The ordinate scale is arbitrary, and the figures on the abscissae are $\AA$.

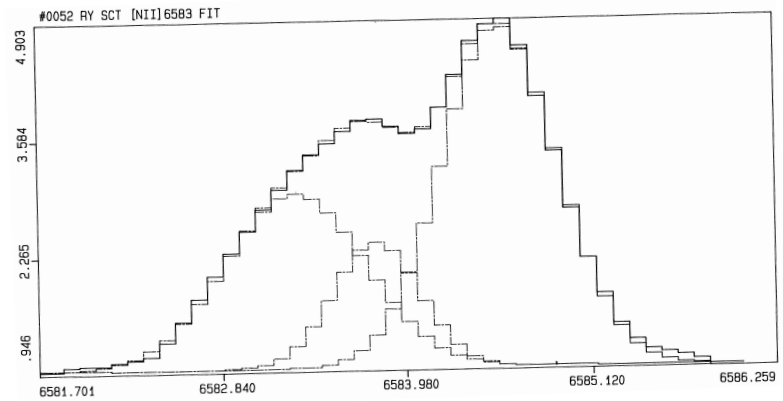

Fig. 9. Components in the [N II] $\lambda 6584$ line of the spectrum of RY Sct. The ordinate scale is arbitrary, and the figures on the abscissae are $\AA$. 
and of Si III 4567. The apparent shift of $\lambda 4560 \AA$ might, therefore, be thought to be the result of the shifts of these absorptions. Indeed, Skul'sky (1985) based his original solution of the orbital elements on the apparent shift of the Si III line, which may arise in the two components of the system. The central part of the $4650 \AA$ emission profile, which is unaffected by the absorption lines, clearly moves, but because of the low $\mathrm{S} / \mathrm{N}$ ratio and the shallowness of the feature, both the Gaussian fitting and the crosscorrelation techniques gave rather divergent values.

\subsubsection{The E4 Emission System}

Cross-correlation of the individual spectra against the mean spectrum in the spectral interval 4670-4700 $\AA$ as well as the alignment of the spectra in order of phase (Fig. 4), strongly suggest that the gaseous mass that produces the He II $4686 \AA$ emission line moves with the secondary star of the system, if we choose to call "secondary" the star that is in front at principal eclipse. The amplitude is of the order of $150 \mathrm{~km} \mathrm{~s}^{-1}$, that is, significantly smaller than that of Si IV 4088, in agreement with the finding of Cowling \& Hutchings (1976).

\subsection{The Absorption Spectrum}

In the absorption spectrum, it is possible to distinguish:

(a) A set of $\mathrm{H}$ and $\mathrm{He}$ I lines which has a total width of $500-600 \mathrm{~km} \mathrm{~s}^{-1}$ (cf. Fig. 10). The He I lines, which are present throughout the entire spectrum, and the $\mathrm{H}$ lines are always distorted by superimposed emission and narrow absorptions, as may be visualized in Fig. 10 in the case of $\mathrm{H} \delta$; in what follows these will be referred to as the A1 absorption system.

(b) A set (A2) of much narrower lines, 250-300 $\mathrm{km} \mathrm{s}^{-1}$ in total width, as measured in the case of Si IV 4088 (Fig. 11), displayed by the rest of the elements present in the spectrum (cf. Table 4).

(c) Strong, narrow absorption features (A3) that are located to the violet of a narrow, strong emission at about $\lambda 3890 \AA$ (Fig. 12).

(d) Strong interstellar features (A4), some of which are also very broad, their wavelengths being listed in Table 7. The Si III profiles at $4552.7 \AA$ must be somewhat distorted by a broad emission that appears to move together with the absorption but with smaller amplitude (cf. Fig. 13).

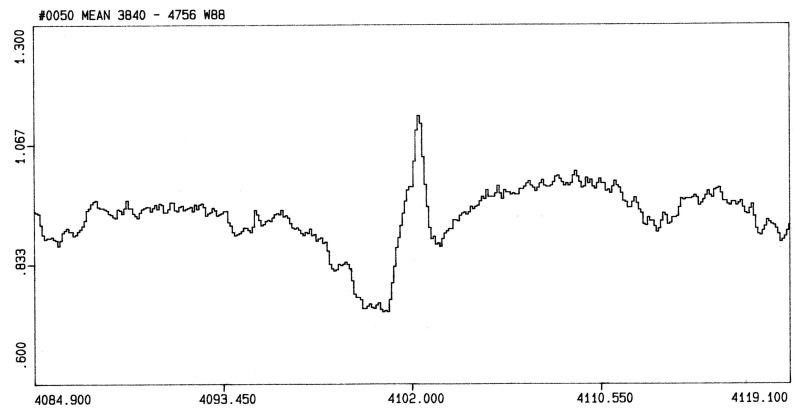

Fig. 10. The region of $\mathrm{H} \gamma$ in the spectrum of RY Sct. The ordinate scale is arbitrary, and the figures on the abscissae are $\AA$.

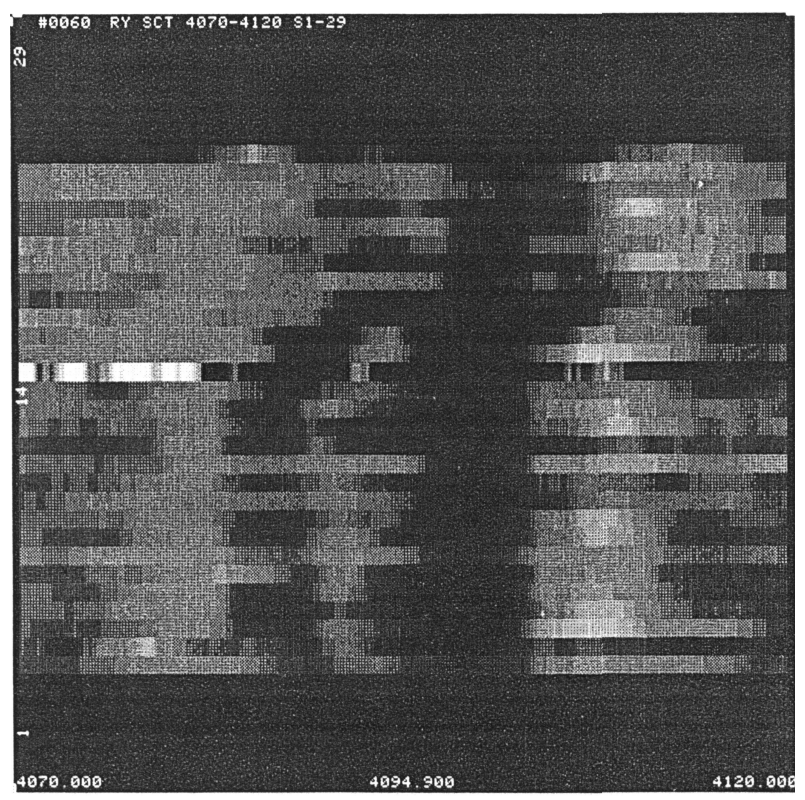

Fig. 11. The region of the absorption line of Si IV $4088 \AA$ in the spectrum of RY Sct throughout the orbital cycle. Strip numbered 14 corresponds to phase 0.275. Phases increase from bottom upwards.

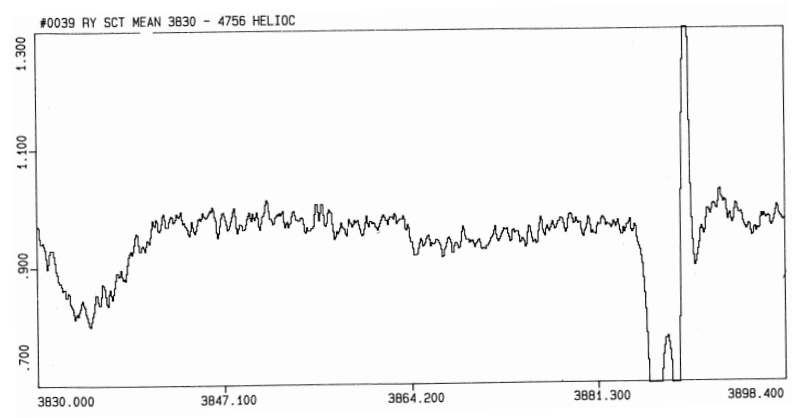

Fig. 12. The region of H I 3888 in the spectrum of RY Sct. The ordinate scale is arbitrary, and the figures on the abscissae are $\AA$. 
TABLE 7

INTERSTELLAR LINES IN THE SPECTRUM OF RY SCUTI

\begin{tabular}{|c|c|c|c|c|c|c|}
\hline Identification $^{\mathrm{a}}$ & $\begin{array}{c}\lambda_{\text {measured }} \\
(\AA)\end{array}$ & Comments & $\begin{array}{c}\mathrm{FWHM}^{\mathrm{b}} \\
(\AA)\end{array}$ & $\begin{array}{l}\mathrm{EW} \\
(\AA)\end{array}$ & \multicolumn{2}{|c|}{$\begin{array}{c}\text { Radial Velocity } \\
\left(\mathrm{km} \mathrm{s}^{-1}\right)\end{array}$} \\
\hline Ca II-K & 3933.60 & & 0.601 & 0.606 & -4.9 & +71.7 \\
\hline Ca II-H & 3968.40 & & 0.614 & & -5.3 & +70.3 \\
\hline $\mathrm{CaI}$ & 4226.80 & & & 0.038 & +5.1 & \\
\hline CH II & 4232.50 & & & 0.028 & & \\
\hline $\mathrm{CH} \mathrm{I}$ & 4300.35 & & & 0.038 & & \\
\hline $\mathrm{H}_{2}$ & 4428.20 & very broad & $22.26^{\mathrm{c}}$ & & & \\
\hline$?$ & 4762.60 & & & & & \\
\hline $\mathrm{Na} I-\mathrm{D}_{2}$ & 5889.80 & & 1.30 & 0.912 & -7.8 & \\
\hline $\mathrm{Na}$ I-D $\mathrm{D}_{1}$ & 5896.00 & & 1.11 & 0.966 & +3.9 & \\
\hline$?$ & 6203.60 & & & & & \\
\hline$?$ & 6270.4 & & & & & \\
\hline$?$ & 6284.2 & & & & & \\
\hline$?$ & 6613.6 & very broad & $8.3^{\mathrm{c}}$ & $2.09^{\mathrm{c}}$ & & \\
\hline Mean value & & & & & $-1.8 \pm 1.34$ & +71.0 \\
\hline
\end{tabular}

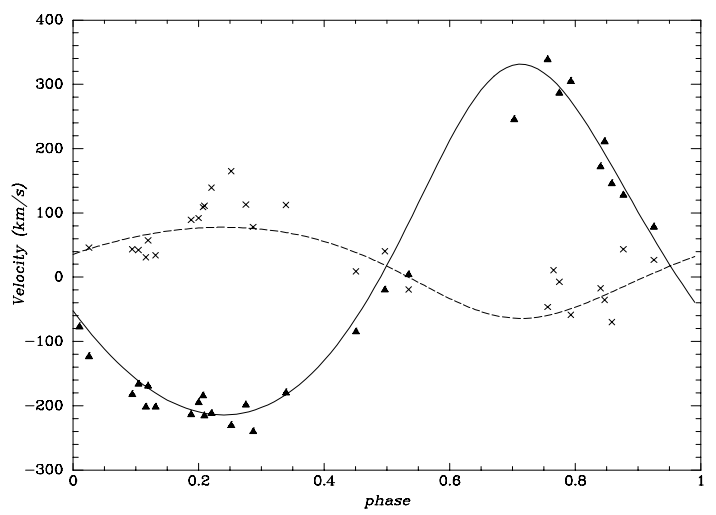

Fig. 13. The orbits of the components of RY Sct. The triangles correspond to the measurements of the He II $4686 \AA$ absorption line and the crosses correspond to the measurements of the emission feature of Si IV $4088 \AA$.

\subsubsection{The A1 Absorption System}

Because of the complex line profiles and low $\mathrm{S} / \mathrm{N}$ ratio, it is impossible to directly measure meaningful orbital radial velocities from any of the broad stellar absorptions in the spectrum of RY Sct. Therefore, we decided to attempt the determination of a velocity curve by the application of the cross-correlation method to the spectral region where the distortion of the lines appear to be the smallest, i.e., to the 3730-3845 A interval. This spectral region contains four Balmer lines (H9-H12) and one helium line (He I
3820 ) that are strong, as well as some much weaker lines of different ions. After truncation of this spectral region, each of the spectra was cross-correlated against the same region in the averages of the spectra taken at phases 0.104 and 0.116 (spectra numbers 4 and 5 in Table 1), and also against the average of the spectra taken at phases 0.200 and 0.207 (spectra numbers 9 and 10 in Table 1). However, this approach did not lead to any reliable determination of the shifts, probably because the lines at the violet end of the region are relatively weaker and because in He I 3820 the E1 emission is comparatively strong. H9 would remain as the only line suitable for radial velocity measurement, although the profile does not appear to be simple.

\subsubsection{The A2 Absorption System}

It might be thought that the A2 lines are actually the same as the A1 lines and that the difference in total width is only the result of a blending effect, perhaps with broad emissions. However, this cannot be so - if it were, then these lines, e.g., Si IV 4088, would have a total width of over $700 \mathrm{~km} \mathrm{~s}^{-1}$. This would, in any case, make them different from the A1 features.

The reality of the presence of two sets of absorption lines that behave differently, in what concerns both the velocity and the width, is clearly illustrated 
in Fig. 11; during the second half of the orbital cycle, the N III 4103 absorption displays a longward shift similar to that of Si IV 4088, and it is definitely larger than that of $\mathrm{H} \delta$.

Among the A2 lines, we select Si IV 4088 for measurement, i.e., the same line that Popper (1943) used to determine the velocity curve of the primary component of the system. This was done by fitting the individual spectra with suitable Gaussian profiles; the radial velocities thus derived are also presented in Table 8 .

\subsubsection{The A3 Absorption System (Fig. 12)}

The spectral profile near $\lambda 3888-90$ displays the strong E1 emission as well as two strong, deep absorptions. The most violet-displaced absorption should obviously be identified with HeI 3889 ; and this identification yields a velocity of $-178 \mathrm{~km} \mathrm{~s}^{-1}$. As for the less violet-displaced feature that corresponds to a wavelength of $3888 \AA$ it must be due to $\mathrm{H} 8$ with some He I blending.

\subsubsection{The A4 Absorption System and the Distance to $R Y$ Sct}

The interstellar lines were identified and measured in the less noisy, mean spectrum of RY Sct, and are listed in Table 7 together with their equivalent widths and radial velocities. The average velocity from five interstellar lines is $-1.8 \pm 1.34 \mathrm{~km} \mathrm{~s}^{-1}$. The $\mathrm{H}$ and $\mathrm{K}$ lines of Ca II display an additional, relatively weak, component at $+71 \mathrm{~km} \mathrm{~s}^{-1}$.

The measured equivalent width of the strongest interstellar Ca II-K component, EW $=0.61 \AA$ when inserted into Evans (1941) relation, gives the distance $d=1.8 \mathrm{kpc}$. Moreover, the strengths of the D lines of Na I yield (cf. Scheffler 1982) a distance of $2.2 \mathrm{kpc}$. We, therefore, conclude that RY Sct is at a distance of $\sim 2 \mathrm{kpc}$, which implies an absolute magnitude $M_{V}=-2.4$ for the system.

The derived value for the distance of RY Sct is in reasonable agreement with the value of $1.6 \mathrm{kpc}$ derived by Milano et al. (1981) on the basis of the star's color excess. Moreover, Zakirov (1985), from photoelectric photometry, concludes that RY Sct is a member of the Ser OB I association, the distance of which is given as $d=1.5 \mathrm{kpc}$ by Lindoff (1968).

All the above mentioned conclusions regarding the distance of RY Sct definitely rule out Banaczkowski \& Dworak's figure of $5 \mathrm{kpc}$ for the actual distance of RY Sct.

\section{THE VELOCITY CURVES}

In summary, there are four sets of lines in the spectrum of RY Sct that behave as if they indicate orbital motion:

(i) E4: the broad emission of He II 4686, with a total amplitude of $\sim 150 \mathrm{~km} \mathrm{~s}^{-1}$;

(ii) A2: the Si IV 4088 and similarly behaved lines, with an amplitude of $\sim 530 \mathrm{~km} \mathrm{~s}^{-1}$;

(iii) A1: the $\mathrm{H}$ and He I broad absorptions, with an amplitude of $\sim 170 \mathrm{~km} \mathrm{~s}^{-1}$

(iv) E3: the emission at $4560 \AA$ (cf. 4.1.3).

The results from He II 4686 suggest, as the alignment of the spectra had already done (Fig. 4), and as mentioned in $\S 4.1 .4$, that this emission arises in a thick envelope that surrounds the star, which is in front at primary eclipse and partakes of its orbital motion. This feature cannot be interpreted in any other way because of the profile displayed as well as because of the velocities involved. Therefore, the He II 4686 line provides information regarding the orbit of the secondary component of the system. Note, however, that Fig. 4 suggests that the violet side of the line is distorted by a neighboring absorption line and, therefore, the actual value of the velocities could be somewhat larger than those in Table 8 .

The existence of some kind of disk around the secondary component of the system indicates that in all probability it is the star that we call the primary component that is losing mass in the system of RY Sct.

We now describe the absorption lines that undergo velocity variations in phase with the orbital motion of the primary component, i.e., the A2 and A1 absorption systems.

The A2 set of lines appears to show no distortion of any kind at any phase, while the A1 set of lines, represented by $\mathrm{H} 9$, are broader and yield very large negative velocities in the phase interval 0.094-0.131. These large approach velocities may be interpreted as arising in a mass of gas streaming from the primary component towards the companion, as is the case in many interacting binaries (cf. $\beta$ Lyrae, for instance). It would be natural to think that Si IV 4088 and the similarly behaved lines (A2) arise in the photosphere of the primary star and reflect the motion on its orbit around the center of gravity of the system. This is supported by the fact that the relevant lines have the relative intensities that correspond to a B0 star.

The H9 line gives a velocity curve with a much smaller amplitude than Si IV, but this is a common, though not yet completely understood, feature in 
TABLE 8

RADIAL VELOCITIES USED FOR THE
ORBITAL SOLUTION OF RY SCT

\begin{tabular}{|c|c|c|}
\hline \multirow{2}{*}{$\begin{array}{l}\text { Phase } \\
(P)\end{array}$} & \multicolumn{2}{|c|}{ Radial Velocity ${ }^{\mathrm{a}}$} \\
\hline & Si IV 4088 & He II 4686 \\
\hline 0.010 & & -77.6 \\
\hline 0.025 & +45.9 & -123.8 \\
\hline 0.094 & +43.3 & -182.8 \\
\hline 0.104 & +42.1 & -166.8 \\
\hline 0.116 & +31.0 & -202.4 \\
\hline 0.119 & +57.1 & -169.7 \\
\hline 0.131 & +34.0 & -202.4 \\
\hline 0.188 & +89.0 & -214.1 \\
\hline 0.200 & +92.0 & -195.4 \\
\hline 0.207 & +108.8 & -185.0 \\
\hline 0.209 & +111.0 & -216.0 \\
\hline 0.220 & +139.2 & -212.4 \\
\hline 0.252 & +165.0 & -231.0 \\
\hline 0.275 & +112.8 & -199.1 \\
\hline 0.287 & +78.3 & -240.7 \\
\hline 0.339 & +112.2 & -180.3 \\
\hline 0.450 & +8.9 & -85.3 \\
\hline 0.496 & +40.4 & -20.2 \\
\hline 0.534 & -19.0 & +3.6 \\
\hline 0.702 & & +244.8 \\
\hline 0.756 & -46.4 & +338.2 \\
\hline 0.765 & +10.7 & \\
\hline 0.774 & -7.1 & +286.1 \\
\hline 0.793 & -58.6 & +304.4 \\
\hline 0.840 & -17.5 & +171.5 \\
\hline 0.846 & -35.6 & +210.6 \\
\hline 0.858 & -70.0 & +145.2 \\
\hline 0.876 & +43.4 & +127.3 \\
\hline 0.925 & +26.8 & +77.6 \\
\hline
\end{tabular}

${ }^{\mathrm{a}}$ Units: $\mathrm{km} \mathrm{s}^{-1}$.

systems whose velocity curves are derived from spectral lines arising in the matter of the gaseous envelope. The above considerations suggest that the orbital elements of the RY Sct system should be derived from a simultaneous solution of the velocities of Si IV 4088 and of He II 4686 (Table 8). This was carried out with the use of the Lehmann-Filhés method and the resulting orbital parameters are listed in Table 9 and illustrated in Fig. 13. With $i=84.6$ (cf. $\S 2$ ), we obtain masses of about $10 M_{\odot}$ for the primary B0 star and $36 M_{\odot}$ for the companion. The
TABLE 9

ORBITAL ELEMENTS OF THE RY SCUTI SYSTEM

\begin{tabular}{llll}
\hline$p$ & 11.1246 & & days \\
$T$ & JD 45107744 & & \\
$e$ & 0.16 & \pm 0.04 & \\
$\omega$ & 344.8 & \pm 15.4 & degrees \\
$V_{\mathrm{o}}$ & 17.4 & \pm 5.0 & $\mathrm{~km} \mathrm{~s}^{-1}$ \\
$K_{1}$ & 272.8 & \pm 13.5 & $\mathrm{~km} \mathrm{~s}^{-1}$ \\
$K_{2}$ & 70.8 & \pm 8.9 & $\mathrm{~km} \mathrm{~s}^{-1}$ \\
$a_{1} \sin i$ & $4.1 \times 10^{7}$ & $\pm 2.06 \times 10^{6}$ & $\mathrm{~km}$ \\
$a_{2} \sin i$ & $1.1 \times 10^{7}$ & $\pm 1.35 \times 10^{6}$ & $\mathrm{~km}$ \\
$M_{1} \sin ^{3} i$ & 9.3 & \pm 1.5 & $M_{\odot}$ \\
$M_{2} \sin ^{3} i$ & 35.8 & \pm 3.8 & $M_{\odot}$ \\
\hline
\end{tabular}

derived values of the system elements are given in Table 8. Fig. 13 suggests that phase 0 in Belserene's photometric elements does not correspond to actual conjunction.

In conclusion - and summarizing the paper-we can say that RY Sct is an interacting binary formed by a $\mathrm{B} 0$ primary of $\simeq 10 M_{\odot}$ and a secondary of $\sim 36 M_{\odot}$, which is surrounded by a thick envelope or disk that emits in He II 4686. The rotational velocity of the B0 star is of the order of $120-150 \mathrm{~km} \mathrm{~s}^{-1}$. The system is caught when the star that is losing mass is already the less massive component, that is, after the mass-ratio reversal has taken place.

The system is embedded in an extended envelope where we can distinguish the following layers:

(a) A region dominated by the gaseous material streaming out from the $\mathrm{B} 0$ component, where the $\mathrm{H}$ and $\mathrm{He} \mathrm{I}$ absorption lines originate.

(b) A region where the broad emission at 4560 $\AA$ originates.

(c) A region of diluted radiation that moves with a velocity of nearly $-180 \mathrm{~km} \mathrm{~s}^{-1}$.

(d) A layer where the expansion velocities reach values of the order of $1000 \mathrm{~km} \mathrm{~s}^{-1}$ and the resonance lines of Si IV and N IV form.

(e) A triple nebulosity with an electron density of the order of $10^{4} \mathrm{~cm}^{-3}$ or perhaps even larger, and velocities of $-18,+9$ and $+48 \mathrm{~km} \mathrm{~s}^{-1}$. The observational evidence seems to support the idea that we are dealing with a sort of protoplanetary nebula that may be an (early?) episode in the rapid mass loss stage, and the question is open as to whether the RY Sct system is in its second episode of mass loss.

In regard to the lines that indicate dilution effect, we may say that, according to Struve \& Wurm's 
(1938) figures, the diluted layer where the strong and narrow absorption of He I 3889 originates is probably located at a distance of more than 5 stellar radii from the star's centre. This layer is moving away from the system at a velocity of about $-180 \mathrm{~km} \mathrm{~s}^{-1}$, and its density is probably not higher than $10^{11} \mathrm{~cm}^{-3}$ or so.

As for the triple nebulosity suggested by the narrow, strong E1 emissions, we are certainly dealing with a low excitation, low density nebula because of the presence of HeI in the spectrum, because of the derived value of $N_{\mathrm{e}}$ (cf. 4.1.1), and because of the steepness of the Balmer decrement (cf. Miyamoto 1952). The three nebular layers move with velocities of $+48,+9$ and $-18 \mathrm{~km} \mathrm{~s}^{-1}$, respectively (§ 4.1.1). In planetary nebulae it is common to find multiple shell structures (e.g., Chu 1989). However, the question regarding the order in which the three nebulosities are located relative to the progenitor cannot be answered at this stage.

It is possible that we are dealing with a protoplanetary nebula. The fact that the characteristics of the infrared excess of the object suggest emission by silicate grains (cf. Aitken et al. 1979; Scott 1983) and the fact that RY Sct is an IRAS source further support this possibility. An additional argument in favor of this hypothesis is provided by Kwok 's (1990) "infrared sequence in the late stages of stellar evolution".

On the other hand, the broader $\mathrm{H}$ and He I absorptions must come from a region where the gas stream is important. The larger width, relative to Si IV and similarly behaved lines, arising from turbulent motions, characterizes this region. The larger eccentricity and smaller amplitude of the velocity curve may be the result of the stream and the gaseous envelope that surrounds the star.

The results suggest that the star that is presently losing mass is the less massive component of the system, the companion displaying a thick disk around it. Therefore, RY Sct is a system in the rapid massloss stage after the mass-ratio reversal has taken place. The question then arises as to whether the sort of protoplanetary nebula displayed would perhaps only be an early episode immediately after the rapid mass-loss stage.

We are grateful to Dr. J. Andersen for kindly putting the SBOP (Spectroscopic Binary Orbital Parameter) program at our disposal. One of us (J.S.) would like to record his gratitude to the staffs of the Cerro Tololo Interamerican Observatory and of the European Southern Observatory at La Silla for their efficient and generous help that made it possi- ble to obtain part of the ground-based material used in the present investigation. J.S. is further indebted to the European Southern Observatory for his appointment as an Unpaid Associate in Garching for two and a half months from September to November 1989, which enabled him to actually devote his time to working on RY Sct. R.M.W. is greatly indebted to the VILSPA staff for all their help when observing the star with the IUE satellite. M.Y.S. is extremely grateful to the International Astronomical Union, through a Commission 38 travel grant, and to the Faculty of Astronomical and Geophysical Sciences, National University of La Plata, Argentina, for a Visiting Professor appointment, which enabled him to spend three months at La Plata, in the latter part of 1997, to work on the present and additional RY Sct material. Useful conversations with Drs. Roberto H. Méndez and Adela E. Ringuelet are gratefully acknowledged. In addition, at La Plata, Guillermo Sierra kindly prepared the illustrations through a computer, María Laura Arias used the INES Archives to print a set of the spectra in the $\lambda 2800$ region, Lydia Cidale produced the graph of the orbital solution and with the assistance of Beatriz Fregenal most kindly prepared the paper for electronic submission. Last but not least, our warm thanks are due to Professor Roy H. Garstang for very kindly making available to us the unpublished supplementary tables to his 1957 paper (MNRAS 117, 393) on the transition probabilities for forbidden lines of Fe III and Fe V. We would finally like to put on record our gratitude to an anonymous referee for his very helpful remarks.

\section{REFERENCES}

Antokhina, E. A. \& Cherepashchuk, A. M. 1988, Lett. Sov. Astron. J., 14, 252

Aitken, D. K., Roche, P. F., Spencer, P. M. \& Jones, B. 1979, ApJ, 233, 925

Banaczkowski, M. \& Dworak, T. Z. 1988, Inf. Bull. Variable Stars No. 3273

Barker, T. 1974, Ph.D. Thesis, Univ. of California, Santa Cruz

Chlebowski, T., Harnden, F. R., Jr. \& Sciortino, S. 1989, ApJ, 341, 427

Ciatti, F., Mammano, A., Margoni, P., Milano, L., Strazzula, G. \& Vittone, A. 1980, A\&AS, 41, 143

Chu, Y. H. 1989, in IAU Symp. 131, Planetary Nebulae, ed. S. Torres-Peimbert (Dordrecht: Kluwer), 105

Cowley, A. P. \& Hutchings, J. B. 1976, PASP, 88, 456

Edlén, B. \& Swings, P. 1939, Observatory, 62, 234

Eissner, W., Martins, P. de A. P., Nussbaumer, H. Saraph, H. E. \& Seaton, M. J. 1969, MNRAS, 146, 63

Evans, J. W. 1941, ApJ, 93, 275 
Gaposchkin, S. 1937, Harvard Ann., 105, 509

Gezari, D. Y., Schmitz, M. \& Mead, J. M. 1987, NASA RP-1196, Catalog of Infrared Observations (Washington, D.C: NASA)

Golovaty, G. I. \& Skul'sky, M. Yu. 1990, in Contr. Astr. Obs. Skalnate Pleso 20, 37

Grasdalen, G. I., Hackwell, J. A., Gehrz, R. D. \& McClain, D. 1979, ApJL, 234, L129

Gurzadyan, G. A. 1969, Planetary Nebulae, transl. P. G. Hummer, C. M. Varsavsky \& Z. Lerman (New York: Gordon \& Breach)

Hegediis, T. 1969, Bull. d'Inf. CDS No. 35, 15

Hughes, V. A. \& Woodsworth, A. 1973, IAU Circ. No. 2488

IRAS 1988, Catalog \& Atlases 4, 321

Kholopov, P. N., Samus, N. N., Frolov, M. S., Goranskij, V. P., Gorijnya, N. A., Karitskaya, E. A., Kazarovets, E. V., Kireova, N. N., Kukarkina, N. P., Medvedieva, G. I., Pastukhova, E. N. \& Shugarov, S. Yu. 1987, General Catalogue of Variable Stars, Vol. 3 (Moscow: Nauka)

King, A. R. \& Jameson, R. F. 1979, A\&A, 71, 326

Kumsiasvili, M. I. 1985, Bull. Abastumani Ap. Obs., 58, 93

Kwok, S. 1990, MNRAS, 244, 179

Lindoff, U. 1968, Archiv f. Astr., 5, 1

Meinel, A. B., Aveni, A. F. \& Stockton, M. W. 1968, Catalogue of Emission Lines in Astrophysical Objects, Optical Sc. Center and Univ. of Arizona Techn. Report No. 27
Milano, L., Vittone, A., Ciatti, F., Mammano, A., Margoni, R. \& Strazzula, G. 1981, A\&A, 100, 59

Miyamoto, S. 1952, PASJ, 4, 28

Nussbaumer, S. 1971, ApJ, 166, 411

O'Connell, D. J. K. 1949, AJ, 54, 1304

Osterbrock, D. E. 1989, Astrophysics of Gaseous Nebulae and Active Galactic Nuclei (Mill Valley, CA: Univ. Sc. Books)

Popper, D. M. 1943, ApJ, 97, 394

Purton, C. R., Feldman, P. A., Marsh, K. A., Allen, D. A. \& Wright, A. E. 1982, MNRAS 198, 321

Sahade, J., Brandi, E. \& Fontenla, J. M. 1984, A\&AS, 56,17

Scheffler, H. 1982, in Landolt-Bernstein: Numerical Data and Fundamental Relationships in Science and Technology, Group VI, Vol. 2c, Astronomy and Astrophysics, eds. K. Schaifers \& H. H. Voigt (Heidelberg: Springer), 55

Scott, P. F. 1983, in IAU Symp. 103, Planetary Nebulae, ed. D. R. Flower, (Dordrecht: Reidel), 61

Seaton, M. J. \& Osterbrook, D. E. 1957, ApJ, 125, 76

Semeniuk, Y. 1968, Acta Astr., 18, 1

Shakhovskoi, N. M. 1965, Soviet Astr., 8, 833 (Astr. Zh., 41, 1042, 1964)

Skul'sky, M. Yu. 1985, Bull. Abastumani Ap. Obs., 58, 101

Struve, O. \& Wurm, K. 1938, ApJ, 88, 89

Walborn, N. R. 1982, AJ, 87, 1300

Zakirov, M. M. 1985, Bull. Abastumani Ap. Obs., 58, 245

Zellner, B. H. \& Serkowski, K. 1972, PASP 84, 619

Jorge Sahade: Facultad de Ciencias Astronómicas y Geofísicas, Universidad Nacional de La Plata, B1900CGALa Plata, Argentina (sahade@fcaglp.unlp.edu.ar).

Richard M. West: European Southern Observatory, D-85748 Garching bei München, Germany (rwest@eso.org).

Mykhailo Yu. Skul'sky: Astronomical Observatory of the Lviv State University, Lvivska Polytechnica, 290646 Lviv, Ukraine (mysky@polynet.lviv.ua). 